\title{
Constraints on dispersal and the evolution of the avifauna of the Northern Hemisphere
}

\author{
KATRIN BÖHNING-GAESE, ${ }^{1,2 *}$ LAURA I. GONZÁLEZ-GUZMÁN ${ }^{3}$ \\ and JAMES H. BROWN ${ }^{3}$ \\ ${ }^{1}$ Lehrstuhl Zoologie/Tierphysiologie, RWTH Aachen, Kopernikusstrasse 16, D-52074 Aachen, Germany, \\ ${ }^{2}$ Vogelwarte Radolfzell, Max-Planck-Institut für Verhaltensphysiologie, D-78315 Radolfzell, Germany and \\ ${ }^{3}$ Department of Biology, University of New Mexico, Albuquerque, NM 87131, USA
}

\begin{abstract}
Summary
One could predict that the capacity for travelling great distances might predispose long-distance migratory birds to be good colonists and to exhibit wider geographic distributions than their non-migratory or shortdistance migratory relatives or non-volant mammals. This prediction is not supported by the data on avian biogeography. The distributions of species, genera and families of North American and Eurasian birds and mammals are indeed related to migratory status, but long-distance migratory birds exhibit a great deal of biogeographic regionalism. In particular, at all taxonomic levels their distributions tend to be confined to either the Eastern or Western Hemisphere, suggesting that there has been little successful east-west dispersal between North America and Eurasia. Compared to non-migratory birds, short-distance migratory birds and non-volant mammals, long-distance migrants appear to be subject to severe constraints on their physiology, behaviour and ecology, which have prevented colonization of distant regions.
\end{abstract}

Keywords: biogeographical distribution; bird migration; Europe; mammal and bird fauna; North America; physiological and behavioural constraints

\section{Introduction}

The composition of a continental fauna has been moulded by evolutionary and ecological processes that operate over a wide range of temporal and spatial scales (Begon et al., 1990; Pianka, 1994). The history of the earth records changes in its geology, climate, oceanography and biota, and these changing environmental conditions have influenced the cladogenetic and anagenetic evolutionary histories of the organisms that experienced them. Brown (1995) calls these two kinds of historical events the 'history of place' and the 'history of lineage', respectively. Currently, spatial and temporal variation in the environment and differences in characteristics of lineages due to their phylogenetic history still interact to limit the abundance, distribution and diversity of organisms. By synthesizing information from recent advances in geology, palaeobiology, phylogenetic systematics, historical biogeography, evolutionary biology and ecology, we are beginning to understand better how the interactions between organisms and their environments over different temporal and spatial scales have influenced biological diversity.

One striking feature of biogeography, recognized at least since Sclater (1858) and Wallace (1876), is that organisms so potentially mobile as flying birds have well-differentiated faunas on the major land masses. Thus, for example, the avifaunas of North America and Eurasia include several families and many genera that are not established on the other continent, even though individual

\footnotetext{
*Address all correspondence to Katrin Böhning-Gaese, Lehrstuhl Zoologie/Tierphysiologie, RWTH Aachen, Kopernikusstrasse 16, D-52074 Aachen, Germany.
} 
birds in these taxa disperse across the North Atlantic and Pacific Oceans with sufficient frequency that bird-watchers record several such 'accidentals' every year (Peterson, 1980, 1990; Peterson et al., 1983). In a still widely cited paper, Mayr (1946) discussed the influence of historical proximity and land connections with Eurasia and South America on the composition of the North American avifauna. He noted that it is composed not only of 'panboreal' lineages that are widely distributed across both the New and Old Worlds, but also of 'pan-American' and 'Old World' elements that are largely confined to either the Western or Eastern Hemisphere. This raises the following question: What characteristics of avian lineages have facilitated or inhibited their historical dispersal, both east-west between the northern continents and north-south within the Eastern and Western Hemispheres?

Flying birds differ greatly in the extent to which they actually disperse. Individuals of some species commute thousands of kilometres and travel between different continents each year on their annual migration, whereas those of other species may spend their entire lives within an area of only a few hectares (Schoener and Schoener, 1983a,b; Villard and Taylor, 1994). The superior capacities of migratory species for long-distance movement is evidenced by the fact that they have longer and more pointed wings than permanent resident species (Winkler and Leisler, 1992). Given these differences in actual and realized capacity to travel long distances, it might be expected that the magnitude and direction of migratory movement would have influenced the historical development of continental avifaunas. An intuitive prediction would be that lineages that contain long-distance migrants should be widely distributed within and among continents and shared between North America and Eurasia, as well as between North and South America or between Europe and Africa, whereas lineages that do not contain migratory species should be more likely to be endemic to single continents or even to regions within continents.

In the present paper, we examine the relationship between migration and the extent of the geographic distribution in North American and European land birds. To evaluate the influence of dispersal capacity on geographic distributions, we also compare the patterns in birds with those in non-volant terrestrial mammals. These two groups of vertebrates share many characteristics. They are both endothermic, with high rates of metabolism, foraging and activity, and both radiated during the Tertiary to fill diverse ecological niches (Vaughan, 1986; Gill, 1989).

Additionally, to evaluate the influence of geological and biogeographic history, we investigate the shape of the biogeographic distributions of the land bird and terrestrial mammal faunas of North America and Europe. These two continents have been widely separated for most of the Tertiary, but Europe has had broad connections with Asia, which has been connected to North America intermittently throughout the Pleistocene by the Bering Land Bridge (Mayr, 1946; Brown and Gibson, 1983). North and South America drifted into proximity during the Tertiary and have been connected by the Interamerican Land Bridge since the Pliocene, about 2.5 million years ago (Webb, 1991). The European fauna has been separated from sub-Saharan Africa by the Mediterranean Sea and the Strait of Gibraltar since at least the early Pliocene, about 5 million years ago. The two biogeographic regions are also isolated from each other by the Sahara Desert, which has been an inhospitable barrier except for short periods during the Pleistocene glaciation (Blondel and Vigne, 1993). We ask which elements of the North American and European avifaunas are shared between these two temperate continents, with tropical South America and with tropical subSaharan Africa. We focus on the question of how the distribution of birds is related to migration.

We analyse quantitatively distributions and their relationships to migratory status at three taxonomic levels: species, genus and family. We do this for two reasons. First, species and higher taxonomic units are usually not considered to represent statistically independent data, because they vary in their phylogenetic relationships to each other. More closely related units would be expected to be more likely to share characteristics (Felsenstein, 1985; Harvey and Pagel, 1991). However, 
this is probably not essential when dealing with the migratory status and range size of large numbers of different bird species. An analysis of 151 German bird species did not reveal phylogenetic effects for migratory status and range size at both landscape and regional spatial scales (Böhning-Gaese and Oberrath, in press). This is confirmed by the fact that migratory behaviour, even within species, is very variable and can change very quickly (Berthold et al., 1990, 1992). Second, it is important to take into account the fact that dispersal processes at biogeographical scales stretch over long periods of time. It may be that long-distance migrants have larger ranges than short-distance migrants or residents at the genus or family level but not at the species level.

\section{Methods}

We included in our analyses all land birds and all non-volant land mammals of North America and Europe following Sibley and Monroe (1990) for birds and Wilson and Reeder (1992) for mammals. While no taxonomic classification can adequately depict the details of the history of a lineage, and the phylogenetic affinities of some avian and mammalian lineages are still topics of debate, these two classes of vertebrates have been the subject of intensive phylogenetic analyses using modern molecular and cladistic techniques. Sibley and Monroe (1990) and Wilson and Reeder (1992) can be assumed to generally reflect phylogenetic relationships. These two books were used primarily because they provide the only phylogenies of birds and mammals that cover in a consistent way the complete faunas of both North American and Europe.

We restricted our analyses to animals that live in, and obtain their resources from, terrestrial habitats, because marine, freshwater and wetland species not only have distinctly different ecological requirements, but they also differ in the way that they perceive and are affected by geographic barriers. We therefore excluded all bird and mammal species that use marine, coastal, freshwater and wetland habitats, such as geese, ducks, waders, storks, gulls, otters, seals and whales. To make our comparison between birds and mammals one between flying and non-volant forms, we excluded bats from the mammalian database. And, finally, we excluded species, such as the Violet-crowned Hummingbird (Amazilia violiceps) or the Barbary Partridge (Alectoris barbara), that have ranges which extend from the south to only marginally enter North America or Europe. North America was defined as that part of the North American continent north of the USMexican border. Europe was defined as that part of the Eurasian land mass west of the Ural Mountains and the Caspian Sea, and north of the Caucasus Mountains, Black Sea and Mediterranean Sea.

We elected to work with the European birds and mammals rather than the entire Eurasian faunas. Although it might be argued that the latter represents a more coherent biogeographic unit, critical data are not available for many Asian species. In particular, the migratory habits of some birds in eastern Asia are poorly known. In addition, Europe is more comparable to North America in being separated from the distinctive biogeographic regions to the south. Currently, Europe is isolated from sub-Saharan Africa by the Mediterranean Sea and the Sahara Desert, and North America is isolated from South America by the Caribbean Sea, by the southwestern deserts, by the Isthmus of Tehuantepec and (farther south) the narrow Isthmus of Panama.

For each species, genus and family of North American and European land bird and mammal, we listed the biogeographic regions (following Brown and Gibson, 1983) where they occur. Distributional data again came from Sibley and Monroe (1990) for birds and from Wilson and Reeder (1992) for mammals. We classified all species, genera and families as Nearctic (restricted to the North American continent north of the Tropic of Cancer), Nearctic/Neotropical (ranging from North America into the tropics south of the Tropic of Cancer), Palearctic (found in Eurasia, and including those forms ranging into Southeast Asia and Australia, but not those extending south of 
the Sahara into southern Africa), Holarctic (found in both the Nearctic and the Palearctic) and Palearctic/Ethiopian (ranging from the Palearctic into Africa south of the Sahara Desert). For migratory birds, we defined the geographical range to include both the breeding and wintering range.

We classified the migratory status of each bird species as resident, short-distance migrant or long-distance migrant. Short-distance migrants were defined as species that regularly wintered south of their breeding range but whose centre of the winter range was for North American species north of the Isthmus of Tehuantepec and for European species north of the Sahara. Long-distance migrants were defined as species whose centre of the winter range was for North American species south of the Isthmus of Tehuantepec and for European species south of the Sahara. In Europe, 13 bird species had migratory routes such that much or all of the wintering range was in Asia rather than Africa. These were defined as short- or long-distance migrants depending on whether the centre of their winter range was north-west or south-east of the Pakistan-Indian border, respectively.

The migratory status of bird genera and families was defined as long-distance if at least one species in the genus or family was a long-distance migrant, as short-distance if at least one species was a short-distance migrant, and the remainder were classified as resident. To test if this definition confounds the results, we also defined bird genera and families in the shorter-distance category. That is, we classified bird genera and families as resident if at least one species in the genus or family was resident, etc. However, this caused only very slight differences in the results.

Chi-square analyses were performed to compare the biogeographic distribution between birds and mammals and among migratory classes in birds. When assumptions of chi-square were not met, statistical analyses were performed using the Fisher's exact test. To avoid repetitive results when testing the extent and shape of biogeographic ranges (Figs 1-4), the analyses were performed combining the data of the North American and European faunas together. In this way, the migratory status of a bird species which was found in both North America and Europe and which had different migratory behaviour on both continents (e.g. resident in Europe, short-distance migrant in North America), was classified in the longer-distance category (in this example: short-distance migrant). When testing for the constraint inhibiting migrants from dispersing east-west between the Nearctic and the Palearctic (Figs 5 and 6), however, we performed separate analyses for Europe and North America, because combining the data would have obscured the pattern.

\section{Results}

As might be expected from their greater dispersal abilities, birds were more widely distributed over biogeographic regions than mammals. We quantified this difference by comparing the percentage of European and North American species, genera and families that occurred in one, two or more than two biogeographic regions (Fig. 1). These results were significant at both the species and genus level and marginally significant at the family level (Table 1).

As expected from their greater dispersal abilities, migrant birds were more widely distributed than resident birds (Fig. 2). These results were significant at both the species and genus level but not at the family level (Table 1). Most of the difference between migrants and residents is caused by the higher percentage of long-distance migrants distributed in two regions (Fig. 2). However, surprisingly few long-distance migrants were found in more than two biogeographic regions. Nevertheless, long-distance migrants had significantly larger biogeographic ranges than shortdistance migrants at the species and genus level but not at the family level (Table 1).

In contrast, resident bird and mammal distributions did not differ significantly from each other at the genus or family level; at the species level, there was a significant difference between both 

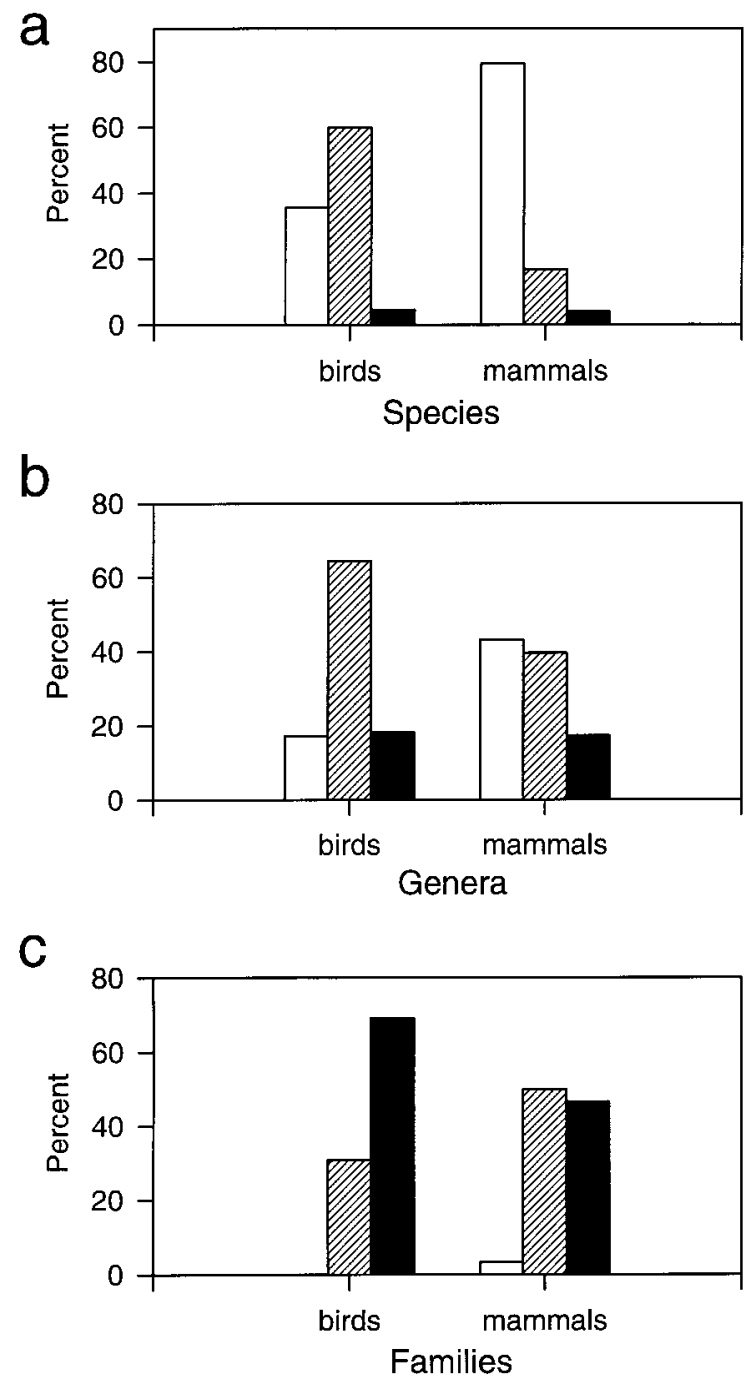

Figure 1. Number of biogeographic regions in which Northern Hemisphere (European and North American) mammal and bird taxa occur: (a) species, (b) genera, (c) families. One region ( $\square$ ), North American or Eurasian endemic; two regions (ש), Eurasian/African or American or Holarctic distribution; three or more regions (ם), Holarctic/African, Holarctic/Neotropical or Holarctic/Neotropical/African distribution. Sample size (species/ genera/families): mammals, 460/139/30; birds, 526/225/39.

distributions, mainly as a result of the higher percentage of mammal species that were endemic to just one continent in the Northern Hemisphere (Fig. 2, Table 1).

For birds in general, compared with mammals, north-south distributions of taxa were observed more frequently than east-west distributions (Fig. 3); that is, avian taxa in North America tended to be shared with South America and those in Europe tended to be shared with Africa, whereas shared distributions between North America and Eurasia were less frequent (Fig. 3). The pattern was tested by comparing for species, genera and families that occurred in two biogeographic 
Table 1. Differences in the extent of biogeographic distributions between birds and mammals and among migratory classes in birds (see Figs 1 and 2): Comparison of the percentages of species, genera and families that occurred in one, two or more than two biogeographic regions

\begin{tabular}{lccl}
\hline & Species & Genera & Families \\
\hline Birds $v$ s mammals & $199.8(2)^{* * * *}$ & $30.8(2)^{* * * *}$ & $3.6(1)^{*, a}$ \\
Migrants $v$ residents & $29.2(2)^{* * * *}$ & $16.1(2)^{* * * *}$ & $\mathrm{~F}(39)$ \\
Long- $v$ short-distance & $51.1(2)^{* * * * *}$ & $11.7(2)^{* * *}$ & $\mathrm{~F}(32)$ \\
Short-distance $v$ residents & $6.6(2)^{* *}$ & $4.9(2)^{*}$ & $\mathrm{~F}(14)$ \\
Residents $v$ mammals & $40.6(2)^{* * * *}$ & $2.0(2)$ & $\mathrm{F} \mathrm{(37)}$ \\
\hline
\end{tabular}

Note: Values are $\chi^{2}$-values with degrees of freedom in parentheses, except where ' $\mathrm{F}$ ' denotes Fisher's exact test with the sample size in parentheses. ${ }^{a}$ Pooling one and two regions.

$* P<0.1, * * P<0.05, * * * P<0.01, * * * * P<0.001$.

regions the percentage that had a north-south distribution with the percentage that had an eastwest distribution. The difference between birds and mammals was significant at both the species and genus level but not at the family level (Table 2).

The difference in the influence of geological history on birds and mammals can be attributed primarily to the influence of migration on the geographic distribution of birds (Fig. 4). This was apparent when birds that differed in migratory status were compared. At both the species and genus levels, the percentage of bird taxa shared between the Nearctic and Neotropical regions and between the Palearctic and Ethiopian regions was significantly higher for migrants than for residents (Table 2). Furthermore, the biogeographic distributions of long-distance and short-distance migrants were significantly different at both the species and genus levels but not at the family level (Fig. 4, Table 2). Distributions of resident birds and mammals did not differ significantly from each other (Fig. 4, Table 2).

The distributions of long-distance migrants in particular suggest that some powerful constraint inhibits them from dispersing east-west between the major land masses (Figs 2 and 4). It appears to be difficult for New World birds to establish migratory routes in the Old World and vice versa. To evaluate the generality of this constraint, we calculated the percentages of North American species, genera and families that occurred not only in America but also in the Palearctic (Fig. 5). In Europe, we calculated the percentages of species, genera and families that were not only Palearctic or Palearctic/Ethiopian but also occurred in the Nearctic (Fig. 6).

In North America, only 4 of 65 long-distance migratory species had east-west distributions such that they also occurred in the Palearctic (Fig. 5): Bank Swallow (Riparia riparia), Barn Swallow (Hirundo rustica), Yellow Wagtail (Motacilla flava) and Northern Wheatear (Oenanthe oenanthe). The last two species, although they have considerable ranges in Alaska, or Alaska and Canada, respectively, indicate their Old World ancestry by migrating to winter in southern Africa and/or Southeast Asia. They have not developed migratory routes within the New World (Peterson, 1980, 1990). Since these species provide some of the strongest support for the constraint hypothesis, we excluded them from further statistical analyses rather than misleadingly including them as North American long-distance migrants. When this was done, the analyses showed that east-west distributions occurred significantly less frequently in long-distance migrants than in residents and short-distance migrants (Table 3).

This pattern was also significant at the genus and family levels (Table 3). At the genus level, only 4 of 32 North American genera that had long-distance migrants also occurred in the Palearctic (Riparia, Hirundo, Buteo and Otus; Fig. 5). However, none of the Palearctic species in the genera 

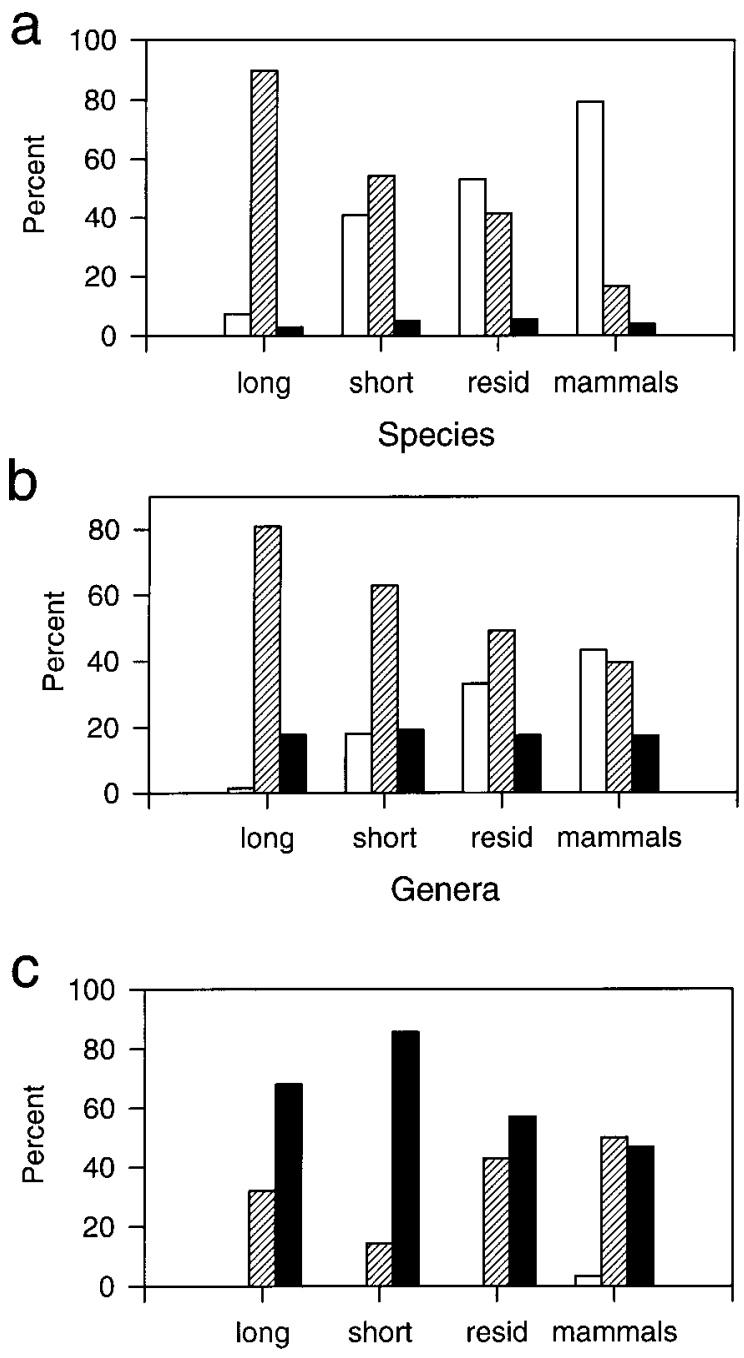

Families

Figure 2. Number of biogeographic regions in which Northern Hemisphere (European and North American) mammal, long-distance migratory, short-distance migratory and resident bird taxa occur: (a) species, (b) genera, (c) families. For key see Fig. 1. Sample size (species/genera/families): mammals, 460/139/30; longdistance migrants, 136/68/25; short-distance migrants, 245/94/7; residents, 145/63/7.

Buteo and Otus were long-distance migrants in Europe. At the family level, 7 of 11 families with long-distance migrants occurred also in the Palearctic (Fig. 5). Four families with long-distance migrants were found only in America (Coccyzidae, Trochilidae, Tyrannidae and Vireonidae). These were the only North American bird families that were endemic to the New World.

In Europe, the same four (out of 75) long-distance migratory species as in North America had east-west distributions that also included the Nearctic (Fig. 6): Bank Swallow, Barn Swallow, Northern Wheatear and Yellow Wagtail. Considering Yellow Wagtail and Northern Wheatear as 

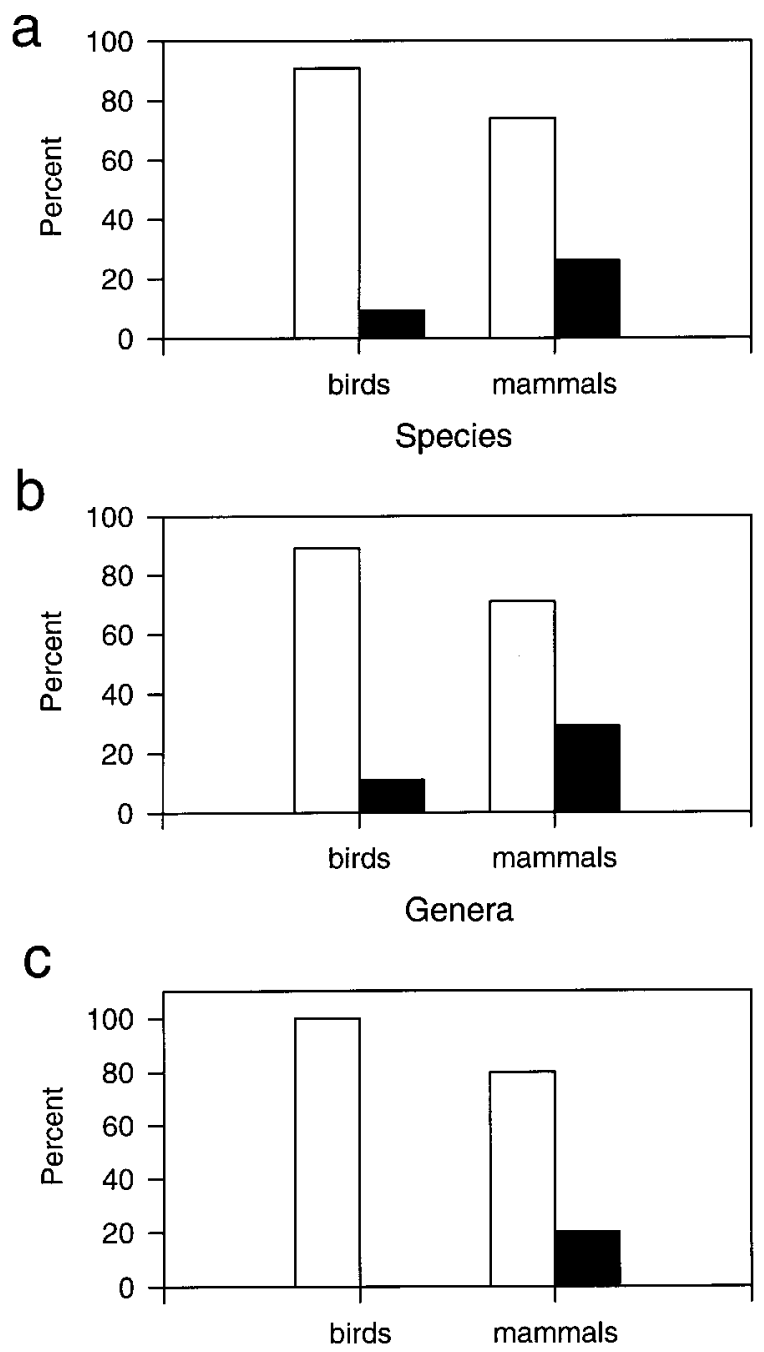

Families

Figure 3. Shape of the biogeographic distribution of Northern Hemisphere (European and North American) bird and mammal taxa that occur in two biogeographic regions: (a) species, (b) genera, (c) families. Northsouth ( $\square$ ), American or Eurasian/African; east-west (ם), Holarctic. Sample size (species/genera/families): mammals, 77/55/15; birds, 315/145/12.

species with Palearctic/Ethiopian distributions, east-west distributions occurred less frequently in long-distance migrants than in residents or short-distance migrants. This pattern was significant at the species and genus levels but not at the family level (Table 3).

In Europe, 8 of 38 genera with long-distance migrants also occurred in the Nearctic (Riparia, Hirundo, Anthus, Caprimulgus, Circus, Falco, Lanius and Sturnus; Fig. 6). However, none of the American species in these genera (except for Riparia and Hirundo as mentioned above) were longdistance migrants in America. At the family level, 15 of 19 families with long-distance migrants 
Table 2. Differences in the shape of biogeographic distributions between birds and mammals and among migratory classes in birds (see Figs 3 and 4): Comparison of the percentages of species, genera and families that had a north-south versus east-west distribution for taxonomic groups that occurred in two biogeographic regions

\begin{tabular}{lcll}
\hline & Species & Genera & Families \\
\hline Birds $v s$ mammals & $15.9(1)^{* * * *}$ & $9.7(1)^{* * * *}$ & $\mathrm{~F}(27)$ \\
Migrants $v$ residents & $17.7(1)^{* * * *}$ & $\mathrm{~F}(145)^{* * *}$ & N.C. \\
Long- $v$ short-distance & $14.6(1)^{* * * *}$ & $\mathrm{~F}(114)^{* *}$ & N.C. \\
Short-distance $v$ residents & $4.7(1)^{* *}$ & $4.1(1)^{* *}$ & N.C. \\
Residents $v$ mammals & $0.1(1)$ & $0.0(1)$ & F (18) \\
\hline
\end{tabular}

Note: Values are $\chi^{2}$-values with degrees of freedom in parentheses, except where ' $F$ ' denotes Fisher's exact test with the sample size in parentheses. N.C., could not be calculated.

** $P<0.05, * * * P<0.01, * * * * P<0.001$.

were found also in the Nearctic. Four families with long-distance migrants were exclusively $\mathrm{Pa}$ learctic/Ethiopian (Coraciidae, Cuculidae, Meropidae and Upupidae).

\section{Discussion}

Before evaluating the implications of our results, we should consider how to interpret different results obtained at different taxonomic levels. Statistical tests at the family level were, in 13 of 16 cases, not significant or could not be calculated (Tables 1-3). Although a lack of significance at the family level might cause the generality of our results to be questioned, in the present case it can be attributed primarily to Type II statistical error (i.e. small sample sizes for families; see also Rosenzweig, 1996) and to the tendency of families to be widely distributed (and therefore to be poor indicators of the constraints of dispersal and geography on distributions; Figs 1-6). Thus, we focus our attention on the patterns at the species and genus levels, which gave similar results in 15 of 16 cases (Tables 1-3). This consistency and the greater similarity of the patterns in non-migratory birds to those in mammals, than to the patterns in migratory birds, suggests that the results were robust with respect to these taxonomic levels, and that the patterns are not simply a consequence of phylogenetic affinity.

The results of our analyses only partly supported the expectation that the high dispersal abilities of flying birds would be reflected in their capacities to colonize across geographic barriers and therefore in their distributions among the major land masses. The extent of geographic ranges of birds and mammals varied as expected from their dispersal abilities: birds were more widely distributed than mammals, and migratory birds were more widely distributed than residents. This is consistent with the suggestion that flight and migration have facilitated dispersal of birds across geographic barriers.

Surprisingly, however, the evolution of long-distance migration has strongly constrained the direction of successful colonizations. Migratory birds, especially long-distance migrants that breed at north temperate and subarctic latitudes and winter in the tropics, are only rarely found in both the New and Old Worlds. Thus, while North America and Europe share multiple species and genera of non-volant mammals and of non-migratory birds, they share few taxa of long-distance migratory birds.

The difficulties migratory birds have experienced in colonizing east to west between the New and Old Worlds cannot be attributed to the ecological severity or historical permanence of the barriers 

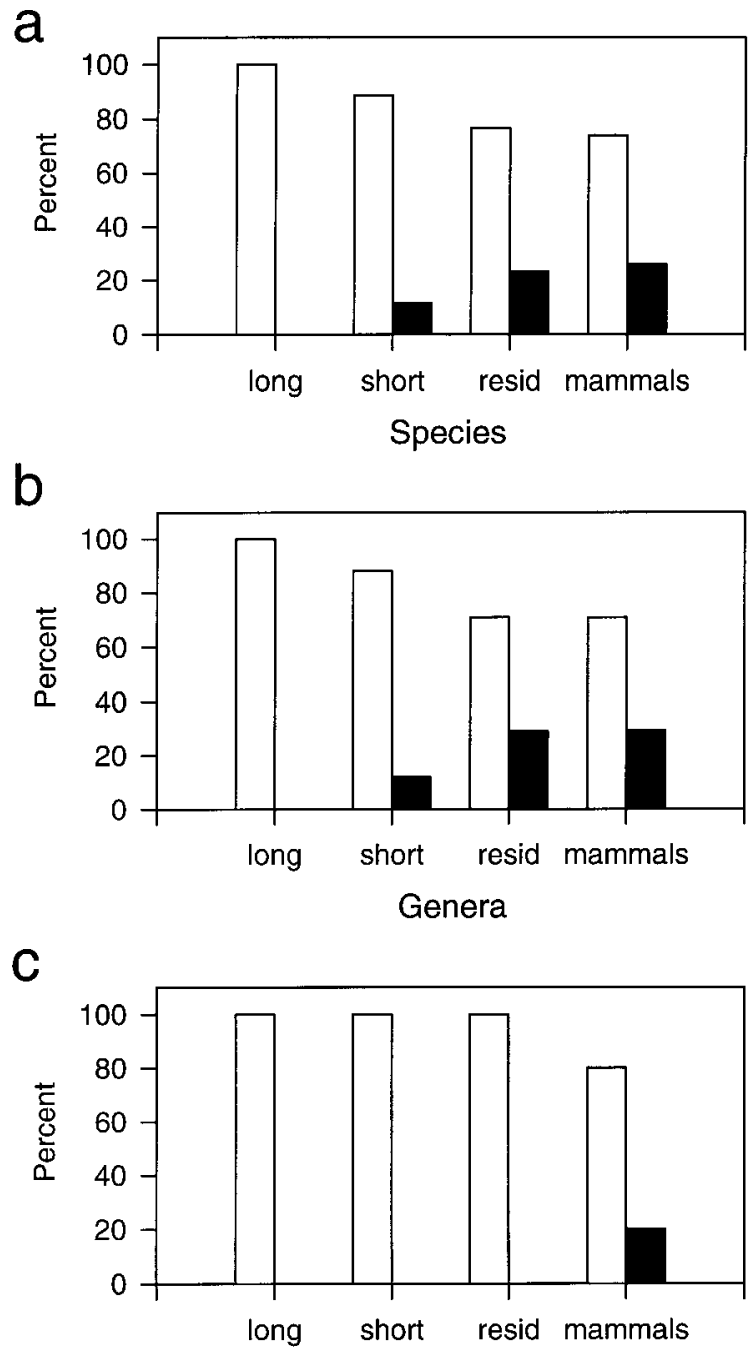

Families

Figure 4. Shape of the biogeographic distribution of Northern Hemisphere (European and North American) mammals and long-distance migratory, short-distance migratory and resident birds: (a) species, (b) genera, (c) families. For key see Fig. 3. Sample size (species/genera/families): mammals, 77/55/15; long-distance migrants, 122/55/8; short-distance migrants, 133/59/1; residents, 60/31/3.

themselves. It is hard to claim that barriers separating North America and Eurasia are any more ancient or severe than those separating the northern continents from the tropical land masses to the south. North America and Eurasia were connected by the Bering Land Bridge during glacial periods of lowered sea levels over the last two million years, and many of the shared species and genera of birds and mammals colonized at those times (Mayr, 1946; Brown and Gibson, 1983). In contrast, North and South America were completely isolated by ocean throughout most of the Tertiary, and they have been connected by a narrow isthmus of tropical habitat for about the last 

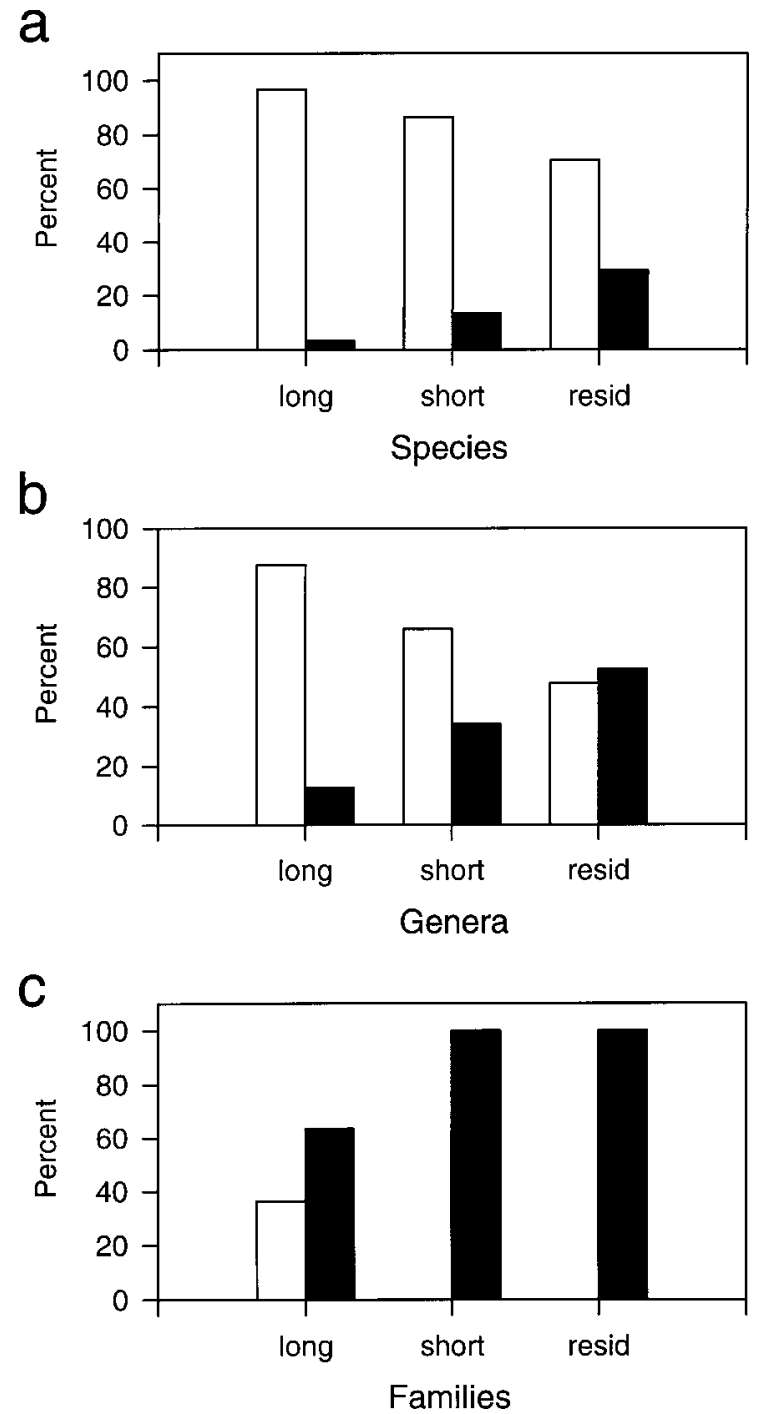

Figure 5. Comparison of the extent to which New World long-distance migratory, short-distance migratory and resident bird taxa are also found in the Old World: (a) species, (b) genera, (c) families. New World ( $\square$ ), taxa endemic to North America or America; additionally Old World (ם), taxa found additionally in the Palearctic. Sample size (species/genera/families): long-distance migrants, 63/32/11; short-distance migrants, 164/79/13; residents, 92/46/7.

3 million years only (Webb, 1991). For much of the Tertiary, Eurasia has been effectively isolated from tropical Africa by the Sahara Desert and the Mediterranean Sea (Brown and Gibson, 1983; Blondel and Vigne, 1993). Furthermore, the migratory routes of such species as the Yellow Wagtail and Northern Wheatear indicate that even the present oceanic barriers separating North America from Eurasia are no obstacle to their dispersal. These species are undoubtedly of Old World 
a

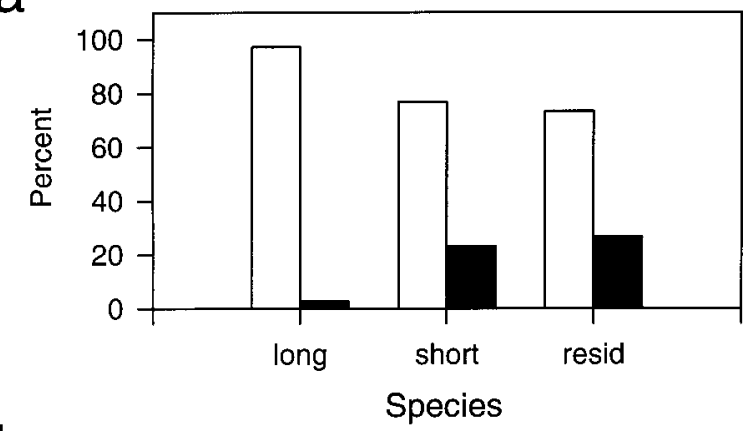

b

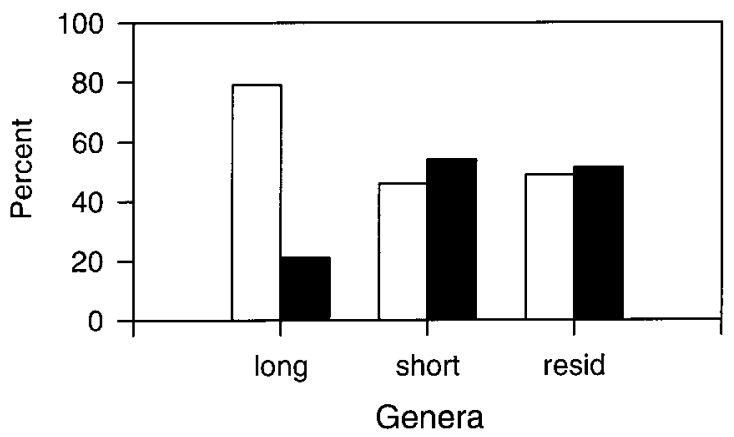

C

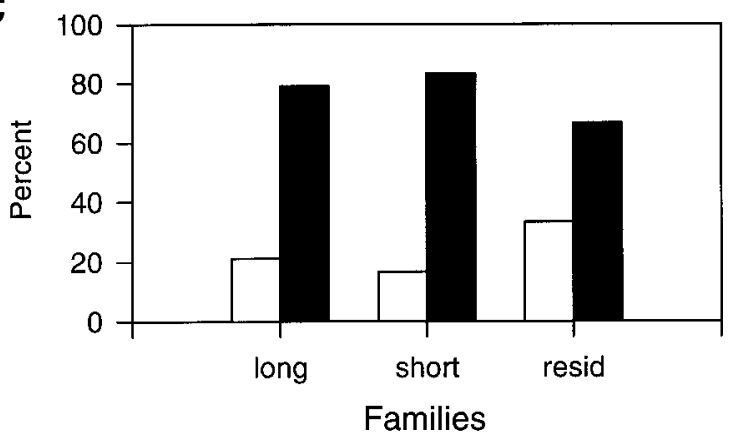

Figure 6. Comparison of the extent to which Old World long-distance migratory, short-distance migratory and resident bird taxa are also found in the New World: (a) species, (b) genera, (c) families. Old World ( $\square$ ),

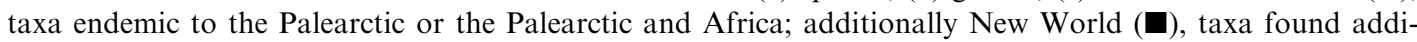
tionally in America. Sample size (species/genera/families): long-distance migrants, 75/38/19; short-distance migrants, 99/37/6; residents, 79/43/9.

ancestry; they breed in the Arctic, primarily in Eurasia, but their breeding ranges extend into North America. It is striking, however, that they migrate back through Eurasia to their wintering grounds in the Old World (Moreau, 1972; Curry-Lindahl, 1981).

The primary difficulty facing a long-distance migrant attempting to colonize between the New and the Old World appears not to be so much the distance, the severity or the historical permanence of the barriers, but rather constraints connected with their migratory behaviour. The ability 
Table 3. Test of the extent to which long-distance migratory species, genera and families are distributed eastwest between Eurasia and North America (see Figs 5 and 6) ${ }^{a}$

\begin{tabular}{|c|c|c|c|}
\hline & Species & Genera & Families \\
\hline \multicolumn{4}{|l|}{ North America } \\
\hline Long $v s$ short + residents & $9.6(1)^{* * *}$ & $9.0(1)^{* * *}$ & $\mathrm{~F}(31)^{* *}$ \\
\hline Long $v s$ short & $5.1(1)^{* *}$ & $5.3(1)^{* *}$ & $\mathrm{~F}(24)^{* *}$ \\
\hline Short vs residents & $9.7(1)^{* * *}$ & $3.9(1)^{* *}$ & N.C. \\
\hline \multicolumn{4}{|l|}{ Europe } \\
\hline Long $v s$ short + residents & $17.3(1)^{* * * *}$ & $10.4(1)^{* * * *}$ & F (34) \\
\hline Long $v s$ short & $14.7(1)^{* * * *}$ & $8.7(1)^{* * *}$ & $\mathrm{~F}(25)$ \\
\hline Short $v s$ residents & $0.3(1)$ & $0.1(1)$ & $\mathrm{F}(15)$ \\
\hline
\end{tabular}

${ }^{a}$ For North America, taxonomic groups occurring exclusively in the New World were compared with groups that, additionally, were found in the Old World. For Europe, taxa occurring exclusively in the Old World were compared with groups that, additionally, were found in the New World.

Note: Values are $\chi^{2}$-values with degrees of freedom in parentheses, except where 'F' denotes Fisher's exact test with the sample size in parentheses. N.C., could not be calculated.

** $P<0.05,{ }^{* * *} P<0.01,{ }^{* * * *} P<0.001$.

of migratory bird species to move to the north to breed and to the south to winter has led to the historical expansion of the geographic ranges of migratory birds, primarily along a north-south axis (Helle and Mönkkönen, 1990).

Over evolutionary time scales, breeding and wintering ranges have moved quite flexibly and independently along this axis. Such changes were necessary for the birds to respond to the dramatic ecological changes that accompanied the glacial-interglacial cycles over the last 2 million years. Flexible migratory patterns are illustrated by variation among species within genera, such as Sylvia and Muscicapa in the Old World and Vireo and Catharus in the New World. For example, within the genus Sylvia, there are long-distance migrants with breeding ranges in Europe and wintering ranges primarily south of the Sahara (seven species, e.g. S. borin), short-distance migrants that breed in Europe and winter primarily in the Mediterranean region (five species, e.g. S. atricapilla), and non-migratory species with ranges both in Europe (one species, $S$. undata) and sub-Saharan Africa (four species, e.g. S. subcaeruleum) (Sibley and Monroe, 1990). Instead of falling into distinct migratory classes, the species are arrayed along a continuum of migratory patterns and geographic ranges. The variability extends even to within species. For example, some populations of Blackcaps (S. atricapilla) winter in Europe, whereas others migrate across the Sahara to winter in subtropical Africa (Curry-Lindahl, 1981).

Even over relatively short time scales, species have been observed to shift their breeding and wintering ranges. Several species in both Europe (e.g. Hippolais polyglotta, Serinus serinus) and North America (e.g. Cardinalis cardinalis, Mimus polyglottos) have expanded their breeding ranges northward during the last century (Sohonen, 1985; Robbins et al., 1986; Bezzel, 1993). Wintering ranges are equally dynamic. With increasing food availability during the winter, former migratory species, such as the European Robin (Erithacus rubecula), have become year-round residents (Berthold, 1993; Bezzel, 1993).

Given the frequency of north-south expansions, especially of long- and short-distance migratory species, the lack of east-west intercontinental colonization by long-distance migrants is all the more striking. That long-distance migration has severely constrained colonization between the New and Old Worlds is apparent from the taxonomic composition of the North American and Eurasian avifaunas. Not only are there essentially no species and genera of long-distance migrants, except for 
some cosmopolitan forms (e.g. Barn and Bank Swallow) that are found on both continents, the same is true at the level of subfamilies and even entire families. Thus, the hummingbirds (Trochilidae), tyrant flycatchers (Tyrannidae), New World cuckoos (Coccyzidae), vireos (Vireonidae) and nighthawks (Chordeilinae) are exclusively New World, while the rollers (Coraciidae), Old World cuckoos (Cuculidae), bee eaters (Meropidae), hoopoes (Upupidae), Old World flycatchers (Muscicapinae) and Old World warblers (Acrocephalinae) are exclusively Old World (Sibley and Monroe, 1990).

Even the exceptions prove the rule. The Winter Wren (Troglodytes troglodytes) is the only species of the wren subfamily (Troglodytinae) (most probably ancestral to the New World) that has colonized Eurasia, where it is primarily non-migratory (Peterson et al., 1983; Sibley and Monroe, 1990). Similarly, the one species of Old World warblers (Sylviidae) living in North America, the Wrentit (Chamaea fasciata), is non-migratory (Peterson, 1990; Sibley and Monroe, 1990). The same holds true for the exotic land bird species that have been successfully introduced from Europe into North America (e.g. the Gray Partridge, Perdix perdix; the Ring-necked Pheasant, Phasianus colchicus; the European Starling, Sturnus vulgaris; and the sparrows, Passer domesticus and $P$. montanus); none of them are long-distance migrants.

In contrast to the great difficulty in dispersing east-west between North America and Eurasia experienced by taxa composed largely or entirely of long-distance migrants, most groups of primarily non-migratory or short-distance migrant land birds are widely distributed across the two land masses. Thus, for example, among the families Phasianidae, Cinclidae, Paridae, Sittidae, Regulidae, Bombycillidae and Certhiidae, there are many genera and a substantial number of species that have wide ranges encompassing both North America and Eurasia (Sibley and Monroe, 1990). This pattern of distribution, reflecting east-west dispersal across the North Pacific and probably also the North Atlantic, is very similar to the one seen in non-volant mammals. The North American and Eurasian mammal faunas share a number of families, genera and even species (e.g. Alces, Canis, Capra, Castor, Cervus, Felis, Lepus, Marmota, Martes, Microtus, Mustela, Ovis, Sciurus, Sorex, Ursus and Vulpes). Thus, the potentially mobile resident and short-distance migratory birds have geographic distributions that resemble those of less vagile mammals in reflecting a history of east-west migration between North America and Eurasia. The potentially more mobile long-distance migrants, however, show a very different pattern: one reflecting north-south dispersal between the temperate zones and the tropics within each hemisphere.

An interesting question, then, is what so powerfully prevents the dispersal of long-distance migratory birds between North America and Eurasia? This question is closely related to the problem of whether the migratory behaviour of a long-distance migrant that colonizes a new continent (e.g. the Northern Wheatear in North America) can be modified. One possible scenario is that the species is able to shift the direction of its migratory behaviour to establish a new migratory pathway on the new continent. This requires that mutations occur in populations of Northern Wheatears that set the stage for the evolution of a new migratory pathway. However, this mutation has to be a macromutational change to be evolutionarily stable.

Long-distance migrants possess a specialized suite of physiological and behavioural characteristics, such as the timing of physiological preparation for migration (e.g. moulting, fat deposition) and the timing, direction and amount of migratory restlessness (Zugunruhe). These physiological and behavioural processes are endogenous (Berthold and Querner, 1981; Berthold et al., 1990), are integrated with and controlled by the annual endocrine cycle, and are cued by photoperiod. While they allow even inexperienced young of the year unaccompanied by adults to migrate to their wintering grounds in their first fall and back to their breeding grounds the following spring, they allow little flexibility in the timing, distance and direction of migration. Additionally, long-distance migrants may also have endogenous capacities to select and utilize distinctive and different habitats and food resources on both their breeding and wintering grounds (Berthold, 1993). 
Thus, a long-distance migratory Northern Wheatear in North America that has a mutation in the direction of its migratory behaviour would also need 'fitting' mutations in the timing and amount of migratory restlessness to end up in a suitable wintering ground. Furthermore, a bird that in spring finds its way back to its old breeding population is faced with the problem that it has to mate with an individual that lacks this mutation. The resulting descendants would show intermediate migratory behaviour (Berthold and Querner, 1981) with a low chance of ending up in an appropriate wintering ground. If the original bird does not find its way back to its old breeding population and colonizes new regions, it would not find a mate. Thus, the constraints against dispersal of long-distance migrants appear primarily to be genetically controlled physiological and behavioural adaptations that are connected with long-distance migration.

The second scenario for east-west dispersal of long-distance migrants might be the evolution of a temperate resident or short-distance migrant as an intermediate stage. This resident or shortdistance migrant might then be able to re-evolve long-distance migration from the north to the south. However, at the species level, this approach lacks empirical evidence. None of the 136 longdistance migratory species shows an intermediate pattern with long-distance migrants on one continent and residents or short-distance migrants on the other continent. All long-distance migrants are either restricted to one continent or are long-distance migrants on both continents. We do find empirical evidence for intermediate distribution patterns, however, at the genus level. In the genera Buteo and Otus, there are long-distance migrants in the New World and only residents and short-distance migrants in Europe. In the genera Anthus, Caprimulgus, Circus, Falco, Lanius and Sturnus, there are long-distance migrants in Europe and only residents and short-distance migrants in North America. However, given these distributions, why did none of these residents and shortdistance migrants evolve long-distance migration from the north to the south?

There seems to exist yet another set of constraints that act against the development of longdistance migration from the north to the south. Forty-nine species of residents and short-distance migrants have distributions covering North America and Eurasia. If these taxa had easily been able to develop long-distance migration independently on both continents, then we would expect a larger number than only two species $(3.9 \%)$ to have done so. Additionally, we would expect at least some species with long-distance migration on one continent and residency or short-distance migration on the other continent. These species, however, do not exist. This strongly supports the suggestion that long-distance migration evolved from the tropics and that long-distance migrants, both in North America and in Europe, are derived from tropical ancestors (Dixon, 1897; Keast, 1980; Rappole and Warner, 1980; Levey and Stiles, 1992; Rappole and Tipton, 1992). We can only speculate about the cause for the constraint against the development of long-distance migration from the north to the south. The reason might be that temperate species have difficulties in 'invading' species-rich tropical communities.

In contrast to long-distance migrants, short-distance migrants appear to be more flexible in their capacity to develop new migratory routes, both in a north-south as well as in a south-north direction. Their migratory behaviour may be less stringently controlled by endogenous factors because they migrate under less severe time and energetic pressures than long-distance migrants (Berthold, 1993). They are probably more flexible in changing the timing, direction and extent of their migratory movements in response to environmental factors, such as natural and humancaused changes in weather, habitat and food supply (Alerstam, 1979; Hagan et al., 1991). For example, beginning about 30 years ago, short-distance migratory Blackcaps from Central Europe evolved a new migratory route and established a new wintering area in the British Isles (Berthold et al., 1992).

Thus, while birds appear to evolve long-distance migration only from the south to the north, short-distance migrants might be derived from different ancestral states. Short-distance migrants 
might have evolved from long-distance migrants that gradually shortened their way to the wintering grounds (e.g. genera Sylvia, Phylloscopus and Catharus). Alternatively, they appear to be derived from residents that moved to the south in particularly cold winters (genus Bombycilla).

In summary, the seemingly paradoxical failure of long-distance migrant birds to colonize eastwest between North America and Eurasia can be explained by severe constraints based on their physiology, behaviour and ecology. Despite their demonstrated capacity for long-distance movement, these species are subject to powerful limitations that prevent the establishment of new colonies in distant locations.

\section{Acknowledgements}

We thank M. Streif for valuable discussion about differences in migratory behaviour between longdistance and short-distance migrants; M. Rosenzweig for valuable suggestions; and D. Schluter, G. Stevens and the students of the 'Biology of migration' class for very helpful comments on the manuscript. Financial support was provided to K.B.-G. by a postdoctoral fellowship of the Deutsche Forschungsgemeinschaft, and to L.I.G.-G. by scholarship 83202 of the Consejo Nacional de Ciencia y Tecnología (CONACyT, México).

\section{References}

Alerstam, T. (1979) Wind as selective agent in bird migration. Ornis Scand. 10, 76-93.

Begon, M., Harper, J.L. and Townsend, C.R. (1990) Ecology. Blackwell Scientific, Oxford.

Berthold, P. (1993) Bird Migration. Oxford University Press, Oxford.

Berthold, P. and Querner, U. (1981) Genetic basis of migratory behavior in European warblers. Science 212, 77-79.

Berthold, P., Mohr, G. and Querner, U. (1990) Steuerung und potentielle Evolutionsgeschwindigkeit des obligaten Teilzieherverhaltens: Ergebnisse eines Zweiweg-Selektionsexperiments mit der Mönchsgrasmücke (Sylvia atricapilla). J. für Ornithol. 131, 33-45.

Berthold, P., Helbig, A.J., Mohr, G. and Querner, U. (1992) Rapid microevolution of migratory behaviour in a wild bird species. Nature 360, 668-670.

Bezzel, E. (1993) Kompendium der Vögel Mitteleuropas. Passeres-Singvögel. Aula Verlag, Wiesbaden.

Blondel, J. and Vigne, J.-D. (1993) Space, time, and man as determinants of diversity of birds and mammals in the Mediterranean region. In Species Diversity in Ecological Communities: Historical and Geographical Perspectives (R.E. Ricklefs and D. Schluter, eds), pp. 135-146. University of Chicago Press, Chicago, IL.

Böhning-Gaese, K. and Oberrath, R. (in press) Phylogenetic effects on morphological, life-history, behavioural and ecological traits of birds. Evol. Ecol. Res.

Brown, J.H. (1995) Macroecology. University of Chicago Press, Chicago, IL.

Brown, J.H. and Gibson, A.C. (1983) Biogeography. C.V. Mosby, St Louis, MO.

Curry-Lindahl, K. (1981) Bird Migration in Africa, Vol. 1. Academic Press, London.

Dixon, C. (1897) The Migration of Birds. Horace Cox, Windsor House, London.

Felsenstein, J. (1985) Phylogenies and the comparative method. Am. Nat. 125, 1-15.

Gill, F.B. (1989) Ornithology. W.H. Freeman, New York.

Hagan, J.M., Lloyd-Evans, T.L. and Atwood, J.L. (1991) The relationship between latitude and the timing of spring migration of North American landbirds. Ornis Scand. 22, 129-136.

Harvey, P.H. and Pagel, M.D. (1991) The Comparative Method in Evolutionary Biology. Oxford University Press, Oxford.

Helle, P. and Mönkkönen, M. (1990) Forest successions and bird communities: Theoretical aspects and practical implications. In Biogeography and Ecology of Forest Bird Communities (A. Keast, ed.), pp. 299318. SPB Academic Publishing, The Hague. 
Keast, A. (1980) Synthesis: Ecological basis and evolution of the Nearctic-Neotropical bird migration system. In Migrant Birds in the Neotropics: Ecology, Behavior, Distribution, and Conservation (A. Keast and E.S. Morton, eds), pp. 559-576. Smithsonian Institute Press, Washington, DC.

Levey, D.J. and Stiles, F.G. (1992) Evolutionary precursors of long-distance migration: Resource availability and movement patterns in Neotropical landbirds. Am. Nat. 140, 447-476.

Mayr, E. (1946) History of the North American bird fauna. Wilson Bull. 58, 1-68.

Moreau, R.E. (1972) The Palaearctic-African Bird Migration Systems. Head, London.

Peterson, R.T. (1980, 1990) A Field Guide to the Birds, 2 vols. Houghton Mifflin, Boston, MA.

Peterson, R.T., Mountfort, G. and Hollom, P.A.D. (1983) A Field Guide to the Birds of Britain and Europe. Collins, London.

Pianka, E.R. (1994) Evolutionary Ecology. Harper Collins, New York.

Rappole, J.H. and Tipton, A.R. (1992) The evolution of avian migration in the Neotropics. Ornitologia Neotropical 3, 45-55.

Rappole, J.H. and Warner, D.W. (1980) Ecological aspects of migrant bird behaviour in Veracruz, Mexico. In Migrant Birds in the Neotropics: Ecology, Behavior, Distribution, and Conservation (A. Keast and E.S. Morton, eds), pp. 353-393. Smithsonian Institute Press, Washington, DC.

Robbins, C.S., Bystrak, D. and Geissler, P.H. (1986) The Breeding Bird Survey: Its First Fifteen Years, 1965 1979. US Fish and Wildlife Service Resource Publication 157, Washington, DC.

Rosenzweig, M.L. (1996) Comment: Colonial birds probably do speciate faster. Evol. Ecol. 10, 681-683.

Schoener, T. and Schoener, A. (1983a) Distribution of vertebrates on some very small islands. I. Occurrence sequences of individual species. J. Anim. Ecol. 52, 209-235.

Schoener, T. and Schoener, A. (1983b) Distribution of vertebrates on some very small islands. II. Patterns in species number. J. Anim. Ecol. 52, 237-262.

Sclater, P.L. (1858) On the general geographical distribution of the members of the class Aves. J. Proc. Linn. Soc. (Zool.) 2, 130-145.

Sibley, C.G. and Monroe, B.L., Jr. (1990) Distribution and Taxonomy of Birds of the World. Yale University Press, New Haven, CT.

Sohonen, T. (1985) Agriculture and birdlife in Finland: A review. Ornis Fennica 62, 47-55.

Vaughan, T.A. (1986) Mammalogy, 3rd edn. W.B. Saunders, Philadelphia, PA.

Villard, M.-A. and Taylor, P.D. (1994) Tolerance to habitat fragmentation influences the colonization of new habitat by forest birds. Oecologia 98, 393-401.

Wallace, A.R. (1876) The Geographical Distribution of Animals, Vols 1 and 2. Macmillan, London.

Webb, S.D. (1991) Ecogeography and the Great American Interchange. Paleobiology 17, 266-280.

Wilson, D.E. and Reeder, D.M. (eds) (1992) Mammal Species of the World: A Taxonomic and Geographic Reference, 2nd edn. Smithsonian Institute Press. Washington, DC.

Winkler, H. and Leisler, B. (1992) On the ecomorphology of migrants. Ibis 134 (suppl. 1), 21-28. 